\title{
Work-family conflict and organizational citizenship behavior: the role of job satisfaction and decision authority
}

Kun Yu, Zhen Wang ${ }^{*}$ and Youhuang Huang

* Correspondence: wangz@ruc.edu. $\mathrm{cn}$

School of Labor and Human Resources, Renmin University of China, Beijing 100872, China

\begin{abstract}
Drawing upon the conservation of resources theory (Hobfoll, Am Psychol 44:513524, 1989), social exchange theory (Blau, Exchange and power in social life, 1964) and the job demand-control model (Karasek, Adm Sci Q 24:285-308, 1979), this study uncovers the theoretical mechanism that explains the relationship between workfamily conflict and organizational citizenship behavior (OCB). First, this study focuses on how employee job satisfaction mediates the relationship. Then, we investigate the moderating role of decision authority in the mediated relationship. We employ three-wave data collected from 324 employees in 102 teams to test our hypotheses. Results of hierarchical linear modeling (HLM) first shows that job satisfaction mediates the relationship between work interference with family (WIF) and OCB. In addition, employees' decision authority moderates the direct effect of WIF on OCB. Specifically, the negative relationship between WIF and OCB is stronger when employees' decision authority is high. Moreover, decision authority moderates the indirect effect of WIF on OCB via job satisfaction. Specifically, the negative relationship between WIF and job satisfaction is weaker when employees' decision authority is high. The results suggest that organizations should give employees enough decision authority over their work, as a high level of decision authority may act as a double-edged sword regarding critical organizational outcomes.
\end{abstract}

Keywords: Work-family conflict, Work interference with family, Organizational citizenship behavior, Social exchange theory, Conservation of resources theory, Job demand-control model

\section{Introduction}

In the last three decades, growing attention has been paid to the interaction of different life domains, such as work and family, as well as the effect of this interaction on individual and organizational outcomes (Rice et al. 1985; Gutek et al. 1991). Given that the role pressures of work and family domains are often incompatible with each other, work-family conflict arises (Greenhaus and Beutell 1985, p.77). Specifically, work interference with family (WIF), referring to the impact of working roles on family life, has received the majority of the research focus on work-family conflict. WIF is more prevalent than family interference with work (FIW) and has more severe consequences than FIW (Frone 2003). Previous evidence has shown that WIF is negatively associated with individuals' job satisfaction (Bedeian et al. 1988; Bacharach et al. 1991) and well-being

(c) The Author(s). 2018 Open Access This article is distributed under the terms of the Creative Commons Attribution 4.0 International License (http://creativecommons.org/licenses/by/4.0/), which permits unrestricted use, distribution, and reproduction in any medium, provided you give appropriate credit to the original author(s) and the source, provide a link to the Creative Commons license, and indicate if changes were made. 
(Matthews et al. 2014; Goh et al. 2015), and positively related to the likelihood of burnout (Pleck et al. 1980), depression (Frone et al. 1992), absenteeism (Goff et al. 2006), and turnover intention (Burke 1988).

Although researchers have associated WIF with attitude and deleterious behavioral outcomes (Eby et al. 2005), to date, few research has considered the impact of work-family conflict on beneficial behaviors, such as $\mathrm{OCB}$, in the workplace (Bragger et al. 2005). Along with work-family conflict, OCB, which refers to employees' proactive behavior that goes beyond their direct role requirements (Smith et al. 1983), is one of the most heavily examined topics in the field of organizational behavior (Levy 2003). Both OCB and WIF are critical in organizations as each of them has a substantial impact on not only individual outcomes but also organizational success (Organ and Ryan 1995; Kossek and Ozeki 1998). Given the influence of WIF and OCB, the dearth of investigation on the relationship between them is surprising. The only exception is Bragger et al. (2005), who found a negative relationship between WIF and OCB. Their use of a cross-sectional sample of teachers and the lack of mediation examination, however, did not allow for the exploration of the mechanism which underlies the relationship between WIF and OCB.

In the present research, we first draw upon the conservation of resources theory (Hobfoll 1989) and social exchange theory (Blau 1964) to investigate the impact of WIF on OCB via both direct resources path and indirect social exchange path. A higher level of WIF occurs when the job "takes" too much of an employee' limited resources and subsequently leads to conflict between work and family life. Based on the conservation of resources theory (Hobfoll 1989), we propose that WIF may lead to individuals' intention to protect their limited resources and, thus, reduce their extra resource investment in extra-role behavior beyond their job duties, such as OCB. Moreover, based on the principle of reciprocity in social exchange theory (Blau 1964), we argue that WIF, as a job demand, leads to individuals' negative feedback towards their job. The negative feedback may include negative attitudes, such as lower job satisfaction, which further leads to the rise of negative behavior or the reduction of positive behavior, such as a lower level of citizenship behavior. Simply put, we expect that the negative relationship between WIF and OCB will be mediated by job satisfaction.

Second, drawing on the job demand-control model (Karasek 1979), we expect that individuals' decision authority, which refers to the possibilities within the organization for workers to make decisions about their work (Karasek 1979), will moderate both the resources path and social exchange path between WIF and OCB. A high level of decision authority, which denotes a high level of job control, is expected to strengthen the negative relationship between WIF and OCB and weaken the negative relationship between WIF and job satisfaction. Combined, we propose that decision authority will simultaneously moderate the direct path from WIF to OCB and the first path of the WIFOCB relationship via job satisfaction (Fig. 1).

\section{Theory and hypotheses}

The impact of WIF on OCB via job satisfaction

Work-family conflict is a type of role conflict that consists of time, strain, and behavioral aspects of conflict between work and family domains, reflecting the incompatibility of 


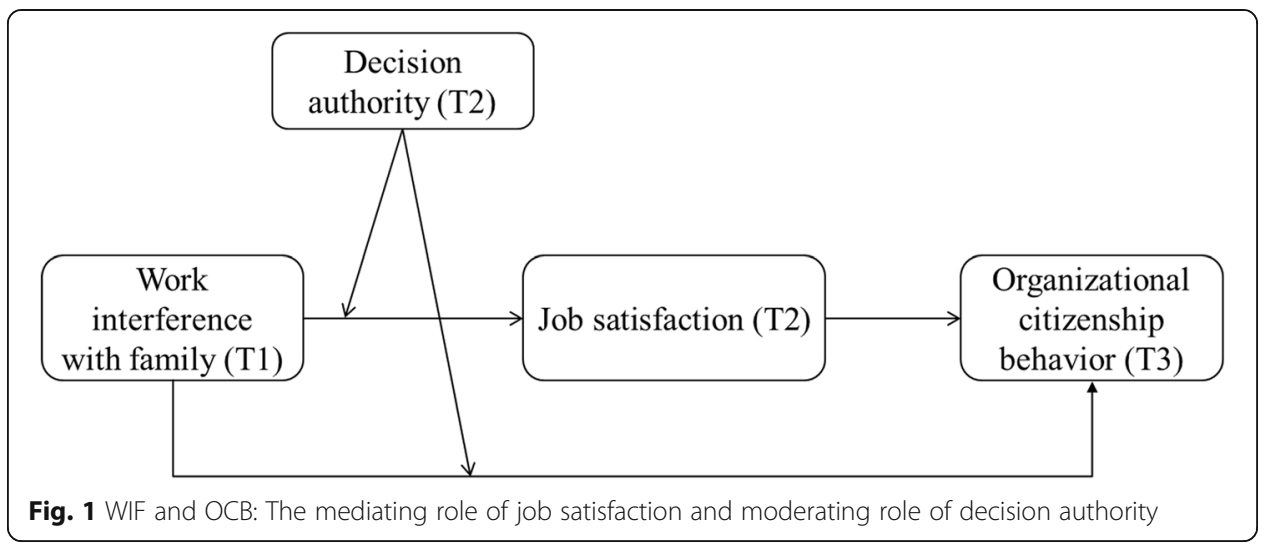

time, emotion, and behavior in work and family life (Greenhaus and Beutell 1985). As a dimension of bidirectional work-family conflict, WIF is a "work-to-family conflict," meaning that the conflict arises due to a person's working role actively interfering with his or her family role (Gutek et al. 1991). According to conservation of resources theory (Hobfoll 1989, 2002), a high level of WIF indicates that too much of an individual's personal resources are used in his or her work settings, and thus insufficient resources are left to cope with family life, which causes conflict between work and family domains (Greenhaus and Beutell 1985). As WIF is a role conflict (Greenhaus and Beutell 1985) that requires employees' attention and effort, it will additionally consume individuals' resources. The resources depleting situation will trigger individuals' resources protection mode, which may at the cost of the worsen of performance (Halbesleben et al. 2009). As a typical type of extra-role performance, OCB requests individuals' time and energy, which can be quit resource-demanding (Bolino and Turnley 2005). Thus, they may not want to spend extra resources on discretionary behavior beyond their job duties. For example, citizenship behavior that needs extra resources invested towards the job may be reduced under a high WIF situation.

Hypothesis 1: Work interference with family is negatively associated with organizational citizenship behavior.

Based on the social exchange theory (Blau 1964), work-family conflict can also be seen as an indicator of how a job "takes" employees' personal resources. We believe individuals under a high level of WIF will be more likely to have negative judgments about their job, indicated by job dissatisfaction. Based on the reciprocal principle in social exchange theory (Blau 1964), individuals who think they do not get resource benefits from their job will be less likely to speak well of their job. Indeed, the negative relationship between work-family conflict and job satisfaction has been supported by several studies (Bacharach et al. 1991; Kossek and Ozeki 1998; Frye and Breaugh 2004). Empirical evidence has also supported the positive relationship between job satisfaction and OCB (Fassina et al. 2007). Research has shown that when employees are not satisfied with their jobs, they are less willing to invest resources in the organization, especially in terms of extra-role performance (Organ 1977; Tyler and Blader 2000). Combining the above reasoning and empirical evidence, we propose that WIF will have 
a negative impact on employees' job satisfaction, which will, in turn, lead to low levels of OCB. '

Hypothesis 2: Job satisfaction will mediate the relationship between work interference with family and organizational citizenship behavior.

\section{The moderating role of decision authority}

Based on conservation of resources theory (Hobfoll 1989, 2002), WIF not only indicates the insufficiency of personal resources but also requires employees' additional resources to deal with it. This resource depletion situation might put individuals into resource protection mode and impede them to spend extra resources on extra-role behaviors, such as OCB. The reduction of citizenship behavior because of WIF is especially salient for individuals with a high level of decision authority in that they have freedom over work-related decisions and control over their jobs (Frese and Fay 2001). With a high level of decision authority, individuals have more autonomy regulating their discretionary behaviors, such as OCB. For these individuals experiencing a high level of WIF, under a threat of resources loss, they are more willing to use resource protection strategies, such as reducing extra-role behaviors that consume additional resources. Simply put, they are more likely to reduce their OCB under a high level of WIF.

In contrast, with low decision authority, individuals' autonomy for behavior regulation is limited. For those individuals experiencing a high level of WIF, they are less likely to use resource protection strategies and to reduce extra-role behaviors. In other words, they are less likely to have low levels of OCB when under a high level of WIF. Thus, we predict that:

Hypothesis 3: Decision authority moderates the relationship between work interference with family and organizational citizenship behavior. Specifically, the negative relationship between them is stronger when decision authority is high.

According to Karasek (1979), the route from WIF to job satisfaction is recognized as a strain path, where the job demand (i.e., WIF) is a stressor that causes employees' stress response, such as dissatisfaction with their job. Besides the strain path hypothesis, the job demand-control model also provides another core prediction, the buffering hypothesis (Karasek 1979; Johnson and Hall 1988; Van der Doef and Maes 1999). The buffering hypothesis denotes that employees' control over work will buffer the adverse effect of job demand on job attitude. Consistent with the buffering hypothesis, decision authority, which is a component of job control in the Job Demand-Control Model, could be a buffer in the negative relationship between WIF and job satisfaction.

With a high level of decision authority, individuals have more control over their decisions and behaviors in the workplace, which can be seen as a type of personal resources (Smoktunowicz et al. 2015). For these individuals experiencing a high level of WIF, they are more able to use personal resources to deal with job demands, and less likely to be dissatisfied with their work. To put it differently, they will be less likely to have a low level of job satisfaction when experiencing a high level of WIF.

In contrast, with a low level of decision authority, individuals' personal resources regarding job control are limited. For these individuals experiencing a high level of WIF, 
they are less able to use their resources to cope with job demands, and are more likely to be dissatisfied with their work. In other words, they are more likely to have a low level of job satisfaction with a high level of WIF. Therefore, we propose that decision authority weakens the negative relationship between WIF and job satisfaction. Moreover, combined with the previous mediation hypothesis, we propose a moderated mediation hypothesis, in which decision authority moderates the indirect effect of WIF on OCB via job satisfaction. Thus, we predict:

Hypothesis 4: Decision authority moderates the relationship between work interference with family and job satisfaction. Specifically, the negative relationship between them is stronger when decision authority is low.

Hypothesis 5: Decision authority moderates the indirect relationship between work interference with family and organizational citizenship behavior via job satisfaction. Specifically, the indirect and negative relationship is stronger when decision authority is low.

\section{Method}

Participants and procedure

Data were collected as part of a large publicly available dataset called the Work, Family, and Health Study (WFHS; Bray et al. 2013). Participants were recruited from the informational technology division of a Fortune 500 company. Data were collected in 3 waves at six-month intervals between each wave. At the baseline (Time 1), 400 employees from 102 work units reported their demographic information and level of work-family conflict. At Time 2, employees' decision authority and job satisfaction were measured. Finally, employees' OCB was measured at Time 3. Among the 400 participants, 324 (response rate $=81 \%$ ) provided completed responses regarding the study variables across all three waves. The average age of the 324 participants was 46.10 years $(\mathrm{SD}=8.49)$. A majority of the sample (62.7\%) self-identified as male. For education level, $17.6 \%$ indicated having a high school degree, and 79.9\% having a bachelor's degree or above. All participants had an average tenure of 13.2 years $(\mathrm{SD}=8.52)$.

\section{Measures}

\section{Work interference with family}

WIF was measured with Netemeyer and Boles' (Netemeyer et al. 1996) five-item work-to-family conflict scale. Participants were asked to think about the past 6 months and rate their agreement on a 5 -point Likert scale (from $1=$ strongly disagree to $5=$ strongly agree). A sample item was "The demands of your work interfere with your family or personal time." The Cronbach's $\alpha$ of WIF for the current dataset was 0.92 .

\section{Decision authority}

Decision authority was measured with a three-item scale adapted from the Job content questionnaire (Karasek et al. 1998). Decision authority assesses one employee's opportunities within the organization to make work-related decisions about their work. Participants were asked to rate their agreement on a 5 -point Likert scale ranging from $1=$ 
strongly disagree to $5=$ strongly agree. Items were "Your job allows you to make a lot of decisions on your own," "On your job, you have very little freedom to decide (reverse coded)," and "You have a lot of say about what happens on your job." The Cronbach's $\alpha$ of the decision authority scale for the current dataset was 0.71 .

\section{Job satisfaction}

Job satisfaction was measured by the three-item scale adopted from Cammann et al. (1983). Participants were asked to rate how satisfied they were with their jobs on a 5 -point Likert scale ranging from $1=$ strongly disagree to $5=$ strongly agree. Items were "In general, you like working at your job," "In general, you are satisfied with your job," and "You are generally satisfied with the kind of work you do in this job." The Cronbach's $\alpha$ of the job satisfaction scale for the current dataset was 0.85 .

\section{Organizational citizenship behavior}

OCB was measured by Lambert's (2000) four-item scale of willingness to help out coworkers. Participants were asked about their relationships with coworkers and to rate their agreement on a 5-point Likert scale ranging from $1=$ never to $5=$ all the time. A sample item was "To what extent do you help other employees with their work when they have been absent?" The Cronbach's $\alpha$ of the OCB scale for the current dataset was 0.73 .

\section{Control variables}

Participants' gender, age, educational level and tenure (by years) were controlled in the current study, as they have been found to affect work-family conflict (Michel et al. 2011).

\section{Results}

Preliminary analysis

Participants in the current study were working in 102 teams, so it was possible that the nested data were non-independent. Thus, intra-class coefficients (ICCs; Shrout and Fleiss 1979) of the study variables were computed. The ICC1s, which indicate the variance explained by group membership, were 0.25 for WIF, 0.07 for decision authority, 0.12 for job satisfaction, and 0.08 for OCB. The ICC2s, which indicate the reliability of group means, were 0.51 for WIF, 0.20 for decision authority, 0.31 for job satisfaction, and 0.22 for OCB. According to Kenny (1995), an ICC1 of 0.01 is considered a small group effect, 0.10 is considered a medium group effect, and 0.15 a large effect. Given that the ICC1s of study variables in the current research ranged from 0.07 to 0.25 when treating the team as a group variable, there was a considerable group effect regarding the current research model. We used a hierarchical linear model (HLM) to eliminate the group effect. Group-level variances of all study variables were controlled in the subsequent analysis.

\section{Tests of discriminant validity}

To examine whether key constructs and covariates in the current study (i.e., WIF at T1, decision authority and job satisfaction at T2, and OCB at T3) were distinguishable from each other, we conducted a confirmatory factor analysis (CFA) using Mplus 7 
(Muthén and Muthén 2012). CFA results indicated that the 4-factor measurement model (i.e., all variables are independent of each other) fitted the data well $\left[\chi^{2}(84)=\right.$ 159.86, $p<0.01$, Comparative Fit Index $(\mathrm{CFI})=0.97$, Tucker-Lewis Index $(\mathrm{TLI})=0.96$, Root Mean Square Error of Approximation (RMSEA) =0.05]. In fact, the 4-factor model fitted the data better than the 3-factor model, in which decision authority and job satisfaction measured in T2 were combined $\left[\chi^{2}(87)=257.80, p<0.01, \mathrm{CFI}=0.93\right.$, $\mathrm{TLI}=0.91$, RMSEA $=0.08$ ], and the one factor model [i.e., all variables were combined, $\left.\chi^{2}(90)=1098.39, p<0.01, \mathrm{CFI}=0.57, \mathrm{TLI}=0.50, \mathrm{RMSEA}=0.19\right]$. These results provided support for the discriminant validity of the constructs in the present study.

The means, standard deviations, correlations and reliabilities among the study variables are presented in Table 1 . WIF was negatively associated with job satisfaction $(r=$ $-0.35, p<0.01$ ), while decision authority was positively associated with job satisfaction $(r=0.49, p<0.01)$. Moreover, WIF was negatively associated with decision authority $(r$ $=-0.24, p<0.01)$. Furthermore, job satisfaction was positively associated with OCB $(r$ $=0.17, p<0.01)$. Finally, WIF was negatively associated with decision authority $(r=-$ $0.13, p<0.05)$.

\section{Hypothesis tests}

To examine the role of decision authority in the relationship between WIF and OCB via job satisfaction, we employed the "direct effect and first stage moderation model" approach (Edwards and Lambert 2007), in which the moderating effect takes place on the direct relationship between an independent variable and a dependent variable and on the first stage of the indirect effect of an independent variable on a dependent variable through a mediator. In our model, job satisfaction played a mediating role in the relationship between WIF and OCB, and decision authority moderated the path from WIF to OCB and the path from WIF to job satisfaction. Thus, there was a conditional direct effect and conditional indirect effect of WIF on OCB at different levels of decision authority. In addition, the hierarchical linear modeling approach of Mplus 7 (Muthén and Muthén 2012) was used to include the group level variances into the analysis, thereby ruling out the possible group effect.

Table 1 Means, standard deviations, and correlations

\begin{tabular}{|c|c|c|c|c|c|c|c|c|c|c|}
\hline Variable & M & $S D$ & 1 & 2 & 3 & 4 & 5 & 6 & 7 & \\
\hline 1. Gender & 1.37 & 0.48 & - & & & & & & & \\
\hline 2. Age & 46.10 & 8.49 & 0.10 & - & & & & & & \\
\hline 3. Education & 4.77 & 0.47 & $-0.16^{* *}$ & $-0.21^{* *}$ & - & & & & & \\
\hline 4. Tenure & 13.20 & 8.52 & $0.18^{* *}$ & $0.49^{* *}$ & $-0.36^{* *}$ & - & & & & \\
\hline 5. WIF (T1) & 3.06 & 0.95 & 0.05 & -0.04 & 0.10 & 0.04 & $(0.92)$ & & & \\
\hline 6. Decision authority (T2) & 3.85 & 0.65 & -0.00 & 0.03 & -0.05 & 0.09 & $-0.24^{* *}$ & $(0.71)$ & & \\
\hline 7. Job satisfaction (T2) & 4.00 & 0.73 & -0.02 & 0.08 & -0.02 & 0.04 & $-0.35^{* *}$ & $0.49^{* *}$ & $(0.85)$ & \\
\hline 8. OCB (T3) & 3.71 & 0.58 & -0.10 & -0.03 & 0.04 & -0.01 & $-0.13^{*}$ & $0.15^{* *}$ & $0.17^{* *}$ & (0.73) \\
\hline
\end{tabular}

Notes. $n=324$. Reliability coefficients are reported along the diagonal. Gender was coded as follows: $1=$ male, $2=$ female; Educational level was coded as follows: $1=$ grade 1 through 8, 2=grade 9 through 11 (some high school), $3=$ grade 12 or higher (high school graduate), $4=$ college $1-3$ years (some college or technical school), $5=$ college 4 years or more (college graduate). ${ }^{*} p<0.05 ;{ }^{* *} p<0.01$ 
Results first revealed that, after controlling for gender, age, educational level and tenure, the relationship between WIF and OCB was significantly negative $(B=-0.08, p<$ 0.05). Thus, Hypothesis 1 was supported. Hypothesis 2 proposed that job satisfaction would mediate the WIF-OCB relationship. After controlling for gender, age, educational level and tenure, the mediating effect of job satisfaction was examined. In order to account for the impact of group variance, the covariance of all the study variables was added to the group level. Results of mediation analysis showed that, after incorporating decision authority as a control in addition to gender, age, educational level and tenure, the indirect effect of WIF on OCB through job satisfaction was significant (estimate $=-0.02, S E=0.01, p<0.05,95 \% \mathrm{CI}=[-0.04,-0.003])$. These results showed that job satisfaction had a significant mediating effect on the WIF-OCB relationship. Therefore, Hypothesis 2 was supported.

Following the procedure suggested by Preacher et al. (2007), the proposed moderation hypothesis (Hypothesis 3) and moderated mediation hypotheses (Hypotheses 4 and 5) were examined. As shown in Table 2, the results first revealed that the interactive effect of WIF and decision authority on OCB was significant (estimate $=-0.15$, $S E=0.05, p<0.01,95 \% \mathrm{CI}=[-0.25,-0.05])$. We also did a simple slopes test at \pm 1 standard deviation of decision authority, the results of which are presented in Fig. 2. WIF was negatively related to OCB for employees with high decision authority $(+1 S D$; estimate $=-0.13, S E=0.05, p<0.01,95 \% \mathrm{CI}=[-0.23,-0.03])$, and not significantly related to $\mathrm{OCB}$ for employees with low decision authority $(-1 S D$; estimate $=-0.06, S E$ $=0.05, n s, 95 \% \mathrm{CI}=[-0.03,0.16])$. Thus, Hypothesis 3 was supported .

Further, the results also revealed that the interactive effect of WIF and decision authority on job satisfaction was significant (estimate $=0.17, S E=0.05, p<0.01,95 \% \mathrm{CI}$ $=[0.08,0.26])$. We also did a simple slopes test at \pm 1 standard deviation of decision authority, the results of which are presented in Fig. 3. The negative relationship between WIF and job satisfaction was significant for employees with low decision authority ( 1 $S D$; estimate $=-0.31, S E=0.05, p<0.01,95 \% \mathrm{CI}=[-0.41,-0.22])$, and less significantly related to job satisfaction for employees with high decision authority $(+1 S D$; estimate $=-0.09, S E=0.04, p<0.05,95 \% \mathrm{CI}=[-0.17,-0.02])$. Thus, Hypothesis 4 was supported.

Table 2 Hierarchical linear regression results of hypothesized effects

\begin{tabular}{llllll}
\hline Predictor & \multicolumn{2}{l}{ Job satisfaction } & & OCB \\
\cline { 2 - 3 } \cline { 5 - 6 } & Estimate & SE & & Estimate & 0.06 \\
\hline Gender & 0.00 & 0.08 & & -0.12 & 0.00 \\
Age & 0.01 & 0.01 & 0.00 & 0.00 \\
Education & -0.06 & 0.09 & 0.04 & 0.07 \\
Tenure & 0.00 & 0.01 & 0.00 & 0.01 \\
WIF & $-0.20^{* *}$ & 0.03 & -0.03 & 0.04 \\
DA & $0.44^{* *}$ & 0.05 & 0.09 & 0.07 \\
WIF $\times$ DA & $0.17^{* *}$ & 0.05 & $-0.15^{* *}$ & 0.05 \\
Job satisfaction & & & $0.12^{*}$ & 0.05 \\
$R^{2}$ & $0.32^{* *}$ & & $0.08^{* *}$ & \\
\hline
\end{tabular}

Notes. $n=324$. DA Decision authority, SE Standard error. ${ }^{*} p<0.05,{ }^{* *} p<0.01$ 


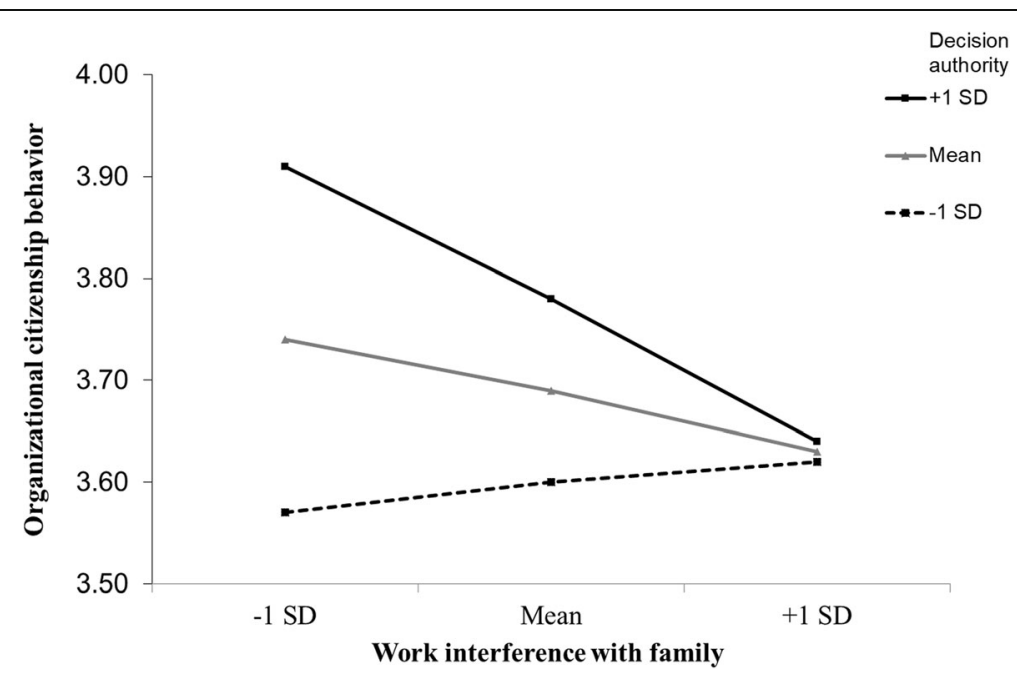

Fig. 2 The interaction effect of WIF and decision authority on OCB (SD = standard deviation)

Moreover, decision authority significantly moderated the indirect effect of WIF on OCB through job satisfaction. Specifically, the indirect effect was significant when decision authority was low $(-1 S D$, estimate $=-0.04, S E=0.02, p<0.05,95 \% \mathrm{CI}=[-$ $0.07,-0.04])$, and not significant when decision authority was high $(+1 S D$, estimate $=-0.01, S E=0.01, n s, 95 \% \mathrm{CI}=[-0.02,0.00])$. The difference in effect size between the high and low conditions was also significant (estimate $=0.03, S E=0.01, p<0.05$, $95 \% \mathrm{CI}=[0.00,0.05])$, indicating that the moderating effect of decision authority on the indirect effect was significant, which supported the moderated mediation hypothesis (Hypothesis 5).

\section{Discussion}

Drawing upon the conservation of resources theory (Hobfoll 1989), social exchange theory (Blau 1964) and the job demand-control model (Karasek 1979), the current study addressed the void in the literature on the relationship between work-family

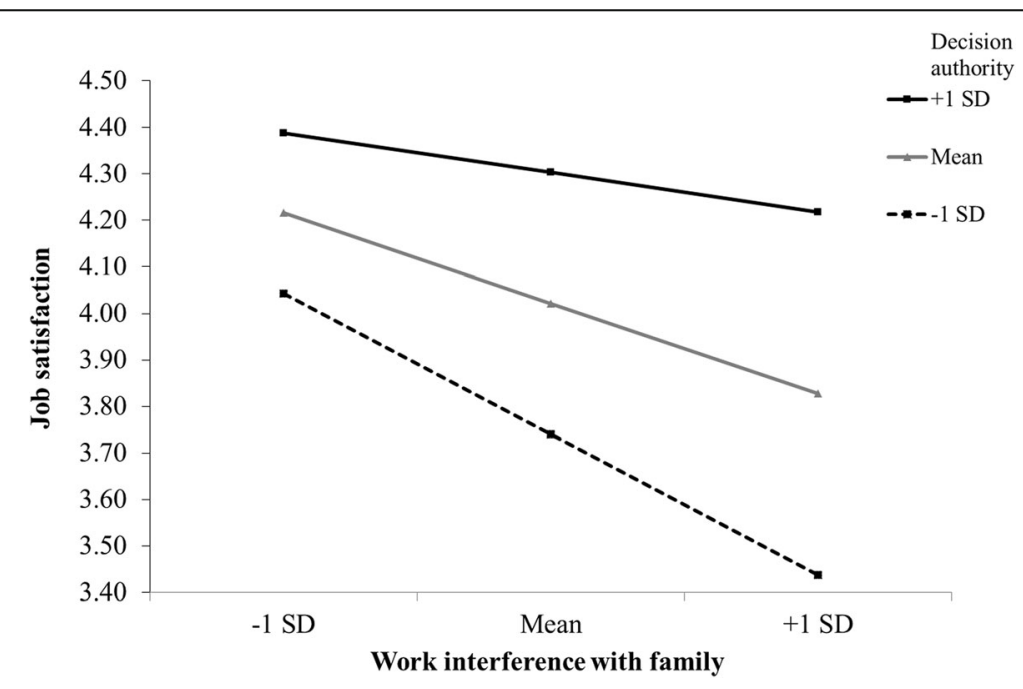

Fig. 3 The interaction effect of WIF and decision authority on job satisfaction (SD = standard deviation) 
conflict and $\mathrm{OCB}$, and investigated the mediating role of job satisfaction and the moderating role of decision authority in this relationship. Specifically, three-wave lagged data were used to examine whether WIF is negatively associated with OCB and whether job satisfaction mediates the WIF-OCB relationship. Furthermore, we also examined how decision authority moderates the direct relationship between WIF and $\mathrm{OCB}$ and the indirect relationship between WIF and OCB via job satisfaction.

Consistent with the conservation of resources theory (Hobfoll 1989), the findings show that WIF negatively relates to OCB, which implies that a reduced level of citizenship behavior may be a strategy for the conservation of resources. As well, consistent with social exchange theory (Blau 1964), job satisfaction mediates the WIF-OCB relationship. This result suggests that WIF associates OCB at least partially through the judgment of the reciprocity of resources exchange (i.e., job satisfaction).

Moreover, consistent with the job demand-control model (Karasek 1979), our results also provide support for the moderating role of decision authority in the direct relationship between WIF and OCB and in the indirect relationship between WIF and OCB via job satisfaction. Decision authority, as job control, plays a strengthening role in the negative WIF-OCB relationship and a buffering role in the negative relationship between WIF and job satisfaction. The above results imply that decision authority, as an indicator of individuals' control over their work-related decisions, on the one hand, may promote personal resources protection (i.e., show less $\mathrm{OCB}$ ) in a resources-demand situation (i.e., WIF) to re-balance resources; and on the other hand, may prevent negative social exchange (i.e., lower job satisfaction) in a high WIF situation.

Our study has contributed to the existing literature on both areas of work-family interface and citizenship behavior in two ways. First, given that little research has addressed the WIF-OCB relationship, let alone investigated the mechanisms or boundary conditions of the relationship, the current study is one of the first to link these two highly examined concepts (i.e., WIF and OCB) in the organizational behavior field and to uncover their relationship with time-lagged data. Drawing upon the conservation of resources theory (Hobfoll 1989) and social exchange theory (Blau 1964), the present study not only examines the direct effect of WIF on OCB but also incorporates job satisfaction as an indicator of social exchange into the WIF-OCB relationship. The findings of the mediating role of job satisfaction in the relationship between WIF and OCB provides novel evidence for the mechanisms or boundary conditions of the WIF-OCB relationship. In sum, the present research paves the way for a clearer picture of the connection between the work-family relationship and extra-role performance.

Second, the findings of the current study also reveals the possible "double-edged" role of decision authority with the incorporation of the job demand-control model. According to social exchange theory (Blau 1964) and the job demand-control model (Karasek 1979), a high level of control over work (i.e., decision authority) could be a buffer in the social exchange relationship between job demands and job attitude. In the current study, job demands (i.e., work-family conflict) are less likely to trigger dissatisfaction for individuals with a high level of decision authority. On the contrary, based on the conservation of resources theory (Hobfoll 1989), we also find that, for individuals with a high level of decision authority, they are more likely to reduce their OCB when experiencing a high level of WIF to protect their personal resources than their low decision authority colleagues. Decision authority, on the one hand, strengthens the 
resource protection path between WIF and OCB and on the other hand weakens the social exchange path between WIF and OCB. The two seemingly contradictory effects may be unified into one purpose by individuals with a high level of decision authority, which is to retain a positive state of resources, including time, energy and emotion (Grawitch et al. 2010). The findings of the differential role decision authority has on job attitude and job behavior shed some light on the job control study, which generally sees job control as a buffer in the job stressor-strain relationship.

The current study has some practical implications as well. Firstly, given that organizations favor employees' citizenship behavior, they should try to provide employees with better working conditions to help them have better work-family balance. During this process, organizations should pay special attention to employees' job satisfaction because it is not only an indicator of employees' work-family balance but is also associated with OCB. At the very least, because job satisfaction is a mediator in the relationship between work-family conflict and OCB, organizations should try to increase job satisfaction in other ways, such as better leadership (e.g., Podsakoff et al. 1990), if work-family conflict is, to some degree, unavoidable.

Secondly, organizations should pay particular attention to policies that give employees control over their work such as decision authority. It is a double-edged sword in that it may, on the one hand, increase job satisfaction or reduce job dissatisfaction but, on the other hand, could also exacerbate the destructive effect of job demands such as work-family conflict on OCB. In the case of dealing with job demands like work-family conflict, organizations could try to provide particular types of support such as work support (Ford et al. 2007), rather than just increase their control over work. That support, based on the job demand-control-support model (Johnson and Hall 1988), could buffer, rather than strengthen the negative relationship between job demands and positive behavior toward the job.

The current study also has some limitations and, accordingly, will provide some future directions. First, although we explore the mechanisms of the WIF-OCB relationship from both resources perspective and social exchange perspective, we only incorporate the indicator of the social exchange path, namely job satisfaction in the WIF-OCB relationship and are still far from fully understanding this relationship. Future research could address this point and develop a model simultaneously incorporating both indicators of resources and social exchange. Second, we only investigate decision authority as a possible boundary condition in the relationship between WIF and OCB. Future research could examine other possible moderators from other perspectives in this relationship. For instance, researchers could draw upon an identity perspective and examine the role of employees' work/family role salience as a moderator. Third, notwithstanding that we have both strengthening and buffering hypothesis about the moderating role of decision authority and both effects are supported, what feature (s) make it an enhancer or a buffer is less clear and more empirical evidence is needed. Future studies could address this issue and examine the mechanism of the effect of decision authority on the path from job demands to job attitude and job behavior. Fourth, considering that decision authority may also increase role demands by having more choices to make in the organization, future research could investigate the curvilinear effect of decision authority on the job demand-attitude relationship where either too little or too much job control is inadequate for individuals. Lastly, although 
we collect data in multiple waves, all study variables are self-reported in nature, which may limit the validity of the relationship proposed. Future studies could try to use more objective measures and multi-source measures (e.g., supervisor ratings of $\mathrm{OCB}$ ) to conduct a stronger test for the WIF-OCB relationship.

\section{Conclusion}

Drawing upon the conservation of resources theory (Hobfoll 1989), social exchange theory (Blau 1964), and the job demand-control model (Karasek 1979), the current study examined the relationship between work-family conflict and OCB with a three-wave data study. Firstly, WIF was found negatively associated with OCB, and this relationship was mediated by job satisfaction. In addition, employees' decision authority moderated the direct effect of WIF on OCB. Specifically, the negative relationship between WIF and OCB was stronger when employees' decision authority was high. Furthermore, decision authority moderated the indirect effect of WIF on OCB via job satisfaction. Specifically, the negative relationship between WIF and job satisfaction was weaker when employees' decision authority was high.

Funding

This article was funded by National Natural Science Foundation of China (Nos. 71101148 and 71702184).

\section{Authors' contributions}

All authors contributed significantly to the manuscript. KY and ZW designed the research and wrote the paper. We added $\mathrm{YH}$ as she contributed substantially during the revision process. YH improved the paper. All authors have approved the manuscript for publication.

Competing interests

The authors declare that they have no competing interests.

\section{Publisher's Note}

Springer Nature remains neutral with regard to jurisdictional claims in published maps and institutional affiliations.

Received: 18 March 2018 Accepted: 7 September 2018

Published online: 19 September 2018

\section{References}

Bacharach, S. B., Bamberger, P. A., \& Conley, S. (1991). Work-home conflict among nurses and engineers: Mediating the impact of role stress on burnout and satisfaction at work. Journal of Organizational Behavior, 12, 39-53.

Bedeian, A. G., Burke, B. G., \& Moffett, R. G. (1988). Outcomes of work-family conflict among married male and female professionals. Journal of Management, 14, 475-491.

Blau, P. M. (1964). Exchange and power in social life. Piscataway: Transaction Publishers.

Bolino, M. C., \& Turnley, W. H. (2005). The personal costs of citizenship behavior: the relationship between individual initiative and role overload, job stress, and work-family conflict. Journal of Applied Psychology, 90, 740-748.

Bragger, J. D., Rodriguez-Srednicki, O., Kutcher, E. J., Indovino, L., \& Rosner, E. (2005). Work-family conflict, work-family culture, and organizational citizenship behavior among teachers. Journal of Business and Psychology, 20, 303-324.

Bray, J. W. J., Kelly, E. L., Hammer, L. B., Almeida, D. M., Dearing, J. W., King, R. B., \& Buxton, O. M. (2013). An integrative, multilevel, and transdisciplinary research approach to challenges of work, family, and health. Methods report. Research Triangle Park: RTI Press.

Burke, R. J. (1988). Some antecedents and consequences of work-family conflict. Journal of Social Behavior and Personality, 3, $287-302$.

Cammann, C., Fichman, M., Jenkins, D., \& Klesh, J. R. (1983). Assessing the attitudes and perceptions of organizational members. In S. E. Seashore, E. E. Lawler, P. H. Mirvis, \& C. Cammann (Eds.), Assessing organizational change: a guide to methods, measures, and practices (Vol. 71, p. 138). New York: Wiley-Interscience.

Eby, L. T., Casper, W. J., Lockwood, A., Bordeaux, C., \& Brinley, A. (2005). Work and family research in IO/OB: Content analysis and review of the literature (1980-2002). Journal of Vocational Behavior, 66, 124-197.

Edwards, J. R., \& Lambert, L. S. (2007). Methods for integrating moderation and mediation: a general analytical framework using moderated path analysis. Psychological Methods, 12, 1-22.

Fassina, N. E., Jones, D. A., \& Uggerslev, K. L. (2007). Relationship clean-up time: Using meta-analysis and path analysis to clarify relationships among job satisfaction, perceived fairness, and citizenship behaviors. Journal of Management, 34, $161-188$.

Ford, M. T., Heinen, B. A., \& Langkamer, K. L. (2007). Work and family satisfaction and conflict: A meta-analysis of cross-domain relations. Journal of Applied Psychology, 92, 57-80.

Frese, M., \& Fay, D. (2001). Personal initiative: An active performance concept for work in the 21st century. Research in Organizational Behavior, 23, 133-187. 
Frone, M. R. (2003). Work-family balance. In Q. JC \& T. LE (Eds.), Handbook of occupational health psychology (pp. 143-162). Washington, DC: American Psychological Association.

Frone, M. R., Russell, M., \& Cooper, M. L. (1992). Prevalence of work-family conflict: are work and family boundaries asymmetrically permeable? Journal of Organizational Behavior, 13, 723-729.

Frye, N. K., \& Breaugh, J. A. (2004). Family-friendly policies, supervisor support, work-family conflict, family-work conflict, and satisfaction: a test of a conceptual model. Journal of Business and Psychology, 19, 197-220.

Goff, S. J., Mount, M. K., \& Jamison, R. L. (2006). Employer supported child care, work-family conflict, and absenteeism: A field study. Personnel Psychology, 43, 793-809.

Goh, Z. W., llies, R., \& Wilson, K. S. (2015). Supportive supervisors improve employees' daily lives: the role supervisors play in the impact of daily workload on life satisfaction via work-family conflict. Journal of Vocational Behavior, 89, 65-73.

Grawitch, M. J., Barber, L. K., \& Justice, L. (2010). Rethinking the work-life interface: It's not about balance, it's about resource allocation. Applied Psychology: Health and Well-Being, 2, 127-159.

Greenhaus, J. H., \& Beutell, N. J. (1985). Sources of conflict between work and family roles. Academy of Management Review, $10,76-88$.

Gutek, B. A., Searle, S., \& Klepa, L. (1991). Rational versus gender role explanations for work-family conflict. Journal of Applied Psychology, 76, 560-568.

Halbesleben, J. R. B., Harvey, J., \& Bolino, M. C. (2009). Too engaged? A conservation of resources view of the relationship between work engagement and work interference with family. Journal of Applied Psychology, 94, 1452-1465.

Hobfoll, S. E. (1989). Conservation of resources: a new attempt at conceptualizing stress. American Psychologist, 44, 513-524

Hobfoll, S. E. (2002). Social and psychological resources and adaptation. Review of General Psychology, 6, 307-324.

Johnson, J. V., \& Hall, E. M. (1988). Job strain, work place social support, and cardiovascular disease: a cross-sectional study of a random sample of the Swedish working population. American Journal of Public Health, 78, 1336-1342.

Karasek, R. A. (1979). Job demands, job decision latitude, and mental strain: implications for job redesign. Administrative Science Quarterly, 24, 285-308.

Karasek, R. A., Brisson, C., Houtman, I., Bongers, P., \& Amick, B. (1998). The job content questionnaire (JCQ): an instrument for internationally comparative assessments of psychosocial job characteristics. Journal of Occupational Health Psychology, 3, $322-355$.

Kenny, D. A. (1995). The effect of nonindependence on significance testing in dyadic research. Personal Relationships, 2, 67-75.

Kossek, E. E., \& Ozeki, C. (1998). Work-family conflict, policies, and the job-life satisfaction relationship: A review and directions for organizational behavior-human resources research. Journal of Applied Psychology, 83, 139-149.

Lambert, S. J. (2000). Added Benefits : the link between work-life benefits and organizational citizenship behavior. Academy of Management Journal, 43, 801-816.

Levy, P. E. (2003). Industrial/organizational psychology: understanding the workplace. Boston: Houghton Mifflin.

Matthews, R. a., Wayne, J. H., \& Ford, M. T. (2014). A work-family conflict/ subjective well-being process model: A test of competing theories of longitudinal effects. Journal of Applied Psychology, 99, 1173-1187.

Michel, J. S., Kotrba, L. M., Mitchelson, J. K., Clark, M. A., \& Baltes, B. B. (2011). Antecedents of work-family conflict: a meta-analytic review. Journal of Organizational Behavior, 32, 689-725.

Muthén, L. K., \& Muthén, B. O. (2012). Mplus User's Guide (7th ed.). Los Angeles: Muthén \& Muthén.

Netemeyer, R. G., Boles, J. S., \& McMurrian, R. (1996). Development and validation of work-family conflict and familywork conflict scales. Journal of Applied Psychology, 81, 400-410.

Organ, D. W. (1977). Inferences about trends in labor force satisfaction: A casual-correlational analysis. Academy of Management Journal, 20, 510-519.

Organ, D. W., \& Ryan, K. (1995). A meta-analytic review of attitudinal and dispositional predictors of organizational citizenship behavior. Personnel Psychology, 48, 775-802.

Pleck, J. H., Joseph, H., Staines, Graham, L., Lang, L., Linda, \& Staines, G. L. (1980). Conflicts between work and family life Monthly Labor Review, 103, 29-32.

Podsakoff, P. M., MacKenzie, S. B., Moorman, R. H., \& Fetter, R. (1990). Transformational leader behaviors and their effects on followers' trust in leader, satisfaction, and organizational citizenship behaviors. Leadership Quarterly, 1, 107-142.

Preacher, K. J., Rucker, D. D., \& Hayes, A. F. (2007). Addressing moderated mediation hypotheses: theory, methods, and prescriptions. Multivariate Behavioral Research, 42, 185-227.

Rice, R. W., McFarlin, D. B., Hunt, R. G., \& Near, J. P. (1985). Organizational work and the perceived quality of life: Toward a conceptual model. Academy of Management Review, 10, 296-310.

Shrout, P. E., \& Fleiss, J. L. (1979). Intraclass correlations: uses in assessing rater reliability. Psychological Bulletin, 86, 420-428

Smith, C. A., Organ, D. W., \& Near, J. P. (1983). Organizational citizenship behavior: its nature and antecedents. Journal of Applied Psychology, 68, 653-663.

Smoktunowicz, E., Baka, L., Cieslak, R., Nichols, C. F., Benight, C. C., \& Luszczynska, A. (2015). Explaining counterproductive work behaviors among police officers: the indirect effects of job demands are mediated by job burnout and moderated by job control and social support. Human Performance, 28, 332-350.

Tyler, T. R., \& Blader, S. L. (2000). Cooperation in groups: Procedural justice, social identity, and behavioral engagement. New York: Psychology Press.

Van der Doef, M., \& Maes, S. (1999). The job demand-control (-support) model and psychological well-being: A review of 20 years of empirical research. Work \& Stress, 13, 87-114. 